\section{Dr. Pagnoux, et al reply}

\section{To the Editor:}

We appreciate the comments by Drs. Garcia-Valladares and Espinoza ${ }^{1}$ regarding our study on granulomatosis with polyangiitis (Wegener's, GPA) persistently localized to one organ².

As emphasized by their patient's case, subglottic stenosis often evolves and can relapse as a limited process in GPA, in the absence of or with only a few other active systemic extra-respiratory tract vasculitis manifestation(s) and/or progress to fibrotic stenosis. Most of these patients with this potentially rapidly life-threatening manifestation represent a difficult therapeutic challenge ${ }^{3}$. Because the response of subglottic stenosis to conventional systemic treatments is, at best, partial and, if so, often only transient, local therapy, mainly based on repeated dilations with or without local injections of corticosteroids, represents the cornerstone of its therapeutic management $t^{4,5}$. The places of tracheal surgery, laser deobstruction, and local injections of other drugs, such as mitomycin, are still being debated and/or must be better analyzed ${ }^{5,6}$.

We have also treated and reported several patients with GPA and subglottic and/or bronchial stenoses. Among the 494 patients entered in the French Vasculitis Study Group database at the time of our analysis, we identified 12 patients with subglottic stenosis, but they also had other disease manifestations, concomitantly and/or later during the course of their disease. In 2 of them, however, the other disease manifestations were "limited" to crusting rhinitis or nondestructive sinus involvement on computerized tomography scans and not always symptomatic or active when subglottic stenosis required therapeutic intervention. As stated in our Methods, and unlike the study by Holle, et $a l^{7}$, we excluded patients who had upper and lower respiratory tract involvement, regardless of the time they occurred for each of these 2 sites during followup. Whether upper (i.e., nose and sinuses) and lower (i.e., trachea, and perhaps main bronchi) respiratory tracts, excluding more distal bronchi and lung parenchyma, should have been considered a single organ [i.e., corresponding to earnose-throat (ENT) involvement] was and remains debatable for our study. In addition, a diagnosis of GPA for antineutrophil cytoplasmic antibodynegative patients with subglottic stenosis as the sole manifestation and no histological evidence of vasculitis remains uncertain, with alternative diagnoses being restricted to atrophic polychondritis, amyloidosis, cancer, and primary (congenital or idiopathic and progressive) or secondary tracheomalacia (after endotracheal intubation, infection, e.g., tuberculosis, mechanical, thermal or caustic injuries, or external trauma). Sarcoidosis can also affect the larynx, but usually in its supraglottic region.

Finally, rituximab has already been used to treat subglottic stenosis in several patients with GPA, often with good, but inconsistent, results. In our experience and as reported by Aries $e t a l^{8}$ it should be noted that the therapeutic response to rituximab for this specific manifestation may be quite long in coming, compared to responses of some other manifestations, like arthritis, pauci-immune glomerulonephritis, or alveolar hemorrhage ${ }^{9}$. Optimal management of these rare but severe and challenging patients with subglottic and/or bronchial stenoses must be multidisciplinary, with ENT specialists and/or respirologists for local followup and therapy, and rheumatologists and/or internists to handle conventional systemic treatments, knowing their relatively limited, transient and/or partial efficacies, especially when subglottic stenosis is due to fibrosis. Hopefully, other agents under investigation or to be identified will further help treat this manifestation.

CHRISTIAN PAGNOUX, MD, MPH, Department of Internal Medicine, Hôpital Cochin, 27 rue du faubourg Saint-Jacques, 75879 Paris Cedex 14, France; MURIEL STUBBE, MD, PhD, Department of Rheumatology, Hôpital Erasme, Brussels, Belgium; LOÏC GUILLEVIN, MD, Department of Internal Medicine, Hôpital Cochin, Paris.

Address correspondence to Dr. Pagnoux;

E-mail: christian.pagnoux@cch.aphp.fr

\section{REFERENCES}

1. Garcia-Valladares I, Espinoza LR. Subglottic stenosis is a form of limited Wegener's granulomatosis. J Rheumatol 2011;38:2268.

2. Pagnoux C, Stubbe M, Lifermann F, Decaux O, Pavic M, Bérezné A, et al. Wegener's granulomatosis strictly and persistently localized to one organ is rare: assessment of 16 patients from the French Vasculitis Study Group database. J Rheumatol 2011; 38:475-8.

3. Hervier B, Pagnoux C, Renaudin K, Masseau A, Pottier P, Planchon B, et al. Endobronchial stenosis in Wegener's granulomatosis [French]. Rev Méd Interne 2006;27:453-7.

4. Waxman J, Bose WJ. Laryngeal manifestations of Wegener's granulomatosis: case reports and review of the literature. J Rheumatol 1986;13:408-11 .

5. Langford CA, Sneller MC, Hallahan CW, Hoffman GS, Kammerer WA, Talar-Williams C, et al. Clinical features and therapeutic management of subglottic stenosis in patients with Wegener's granulomatosis. Arthritis Rheum 1996;39:1754-60.

6. Hernandez-Rodriguez J, Hoffman GS, Koening CL. Surgical interventions and local therapy for Wegener's granulomatosis. Curr Opin Rheumatol 2010;22:29-36.

7. Holle JU, Gross WL, Holl-Ulrich K, Ambrosch P, Noelle B, Both $\mathrm{M}$, et al. Prospective long-term follow-up of patients with localised Wegener's granulomatosis: does it occur as persistent disease stage? Ann Rheum Dis 2010;69:1934-9.

8. Aries PM, Hellmich B, Voswinkel J, Both M, Nolle B, Holl-Ulrich $\mathrm{K}$, et al. Lack of efficacy of rituximab in Wegener's granulomatosis with refractory granulomatous manifestations. Ann Rheum Dis 2006;65:853-8

9. Aouba A, Pagnoux C, Bienvenu B, Mahr A, Guillevin L. Analysis of Wegener's granulomatosis responses to rituximab: current evidence and therapeutic prospects. Clin Rev Allergy Immunol 2008;34:65-73.

J Rheumatol 2011;38:10; doi:10.3899/jrheum.110494 